\title{
Correction to: It Don't Affect Them Like it Affects Us: Disenfranchised Grief of Black Boys in the Wake of Peer Homicide
}

\author{
Amber Jean-Marie Pabon ${ }^{1}$ (D) . Vincent Basile ${ }^{2}$
}

Published online: 20 December 2021

(c) Springer Nature B.V. 2021

\section{Correction to: The Urban Review https://doi.org/10.1007/s11256-021-00605-2}

The original version of this article unfortunately contained an error in "Abstract" section.

In Abstract section, all the cited references must be removed and the correct Abstract section should read as.

Black boys' grief coping with peer homicide remains under-researched and undertheorized. This is especially significant when combined with the emerging understanding that Black boys may experience homicidal death in significantly different ways and durations than others. This manuscript examines the experiences of three Black boys attending an urban school in the wake of the homicidal death of a peer. We purport the absence of grief counselors, and the lack of administrative sensitivity created a misalignment between the boys' need to grieve, and systems within an urban school context that denied and erased trauma. Drawing from concepts of disenfranchised grief, we situate our analysis using a theory of proximal processes. This framework reveals a perspective that counters the hegemonic ontologies which deny Black boys' the right to grieve. Furthermore, in examining one Black male mentor's support of the boys in the aftermath of this tragedy, this manuscript contributes to an increased awareness of the need for urban school policies and practices that reflect reframed understandings of Black boys' mourning.

The original article has been corrected.

The original article can be found online at https://doi.org/10.1007/s11256-021-00605-2.

Amber Jean-Marie Pabon

amberjeanmarie@gmail.com

1 Secondary Education, Kutztown University of Pennsylvania, Kutztown, USA

2 University of Colorado Boulder, Boulder, USA 
Publisher's Note Springer Nature remains neutral with regard to jurisdictional claims in published maps and institutional affiliations. 